\title{
Effects of maltodextrin on physicochemical properties of freeze-dried avocado powder
}

\author{
${ }^{1, *}$ Chuacharoen, T., ${ }^{1}$ Moolwong, J. and ${ }^{2}$ Chysirichote, T. \\ ${ }^{1}$ Faculty of Science and Technology, Suan Sunandha Rajabhat University, 1 U Thong Nok Rd, Dusit, \\ Bangkok 10300, Thailand \\ ${ }^{2}$ Department of Food Engineering, School of Engineering, King Mongkut's Institute of Technology \\ Ladkrabang, 1 Chalongkrung 1, Chalongkrung Rd, Ladkrabang, Bangkok 10520, Thailand
}

\author{
Article history: \\ Received: 16 December 2020 \\ Received in revised form: 31 \\ January 2021 \\ Accepted: 29 May 2021 \\ Available Online: 12 \\ December 2021 \\ Keywords: \\ Freeze-dried avocado \\ powder, \\ Moisture sorption isotherm, \\ Glass transition temperature, \\ Degree of caking, \\ Antioxidant capacity
}

DOI:

https://doi.org/10.26656/fr.2017.5(6).739

\begin{abstract}
The effect of maltodextrin on the moisture sorption isotherm, glass transition temperature $\left(T_{g}\right)$, and degree of caking of freeze-dried avocado samples at room temperature $\left(25^{\circ} \mathrm{C}\right)$ was investigated. The incorporation of maltodextrin reduced the water sorption capacity of the powder due to its less hygroscopic nature. Parameters derived from the Guggenheim, Anderson, and de Boer (GAB) model describing the properties of absorbed water are discussed. The water absorption isotherm possessed the characteristic sigmoid-shaped type II isotherm curves and the model gave the best fit over the whole range of $a_{w}$ tested. The differential scanning calorimetric method was used to measure the $T_{g}$ of freeze-dried avocado samples. Increasing the water content decreased the $T_{g}$, and $T_{g}$ was increased with increasing maltodextrin content. Increased maltodextrin content to solid material in the freeze-dried sample was associated with less sensitivity to caking as evidenced by $T_{g}$ values. In addition, increased maltodextrin content in the powders caused brighter, less yellowish, and more greenish coloration and protected color change including browning index. The antioxidant capacity was significantly decreased with increasing maltodextrin content. Thus, the effect of maltodextrin concentration on physicochemical properties was a promising way to preserve the physical property and chemical compounds in freezedried avocado powder.
\end{abstract}

\section{Introduction}

The consumption of fruits and vegetables containing high amounts of fiber and phytochemical agents plays an essential role in the maintenance of healthy eating. The avocado (Persea americana Mill.) is a subtropical fruit native to Mexico, and it has recently been a popular fruit to grow in northern of Thailand. It contains high amounts of fats that are saturated and unsaturated fatty acids, carbohydrates, proteins, dietary fibers, vitamins, minerals, and phenol derivatives such as carotenoids (Alkhalaf et al., 2019). Considering its high nutritional value from the richness in phytochemical composition, the avocado possesses numerous health benefiting properties, such as antioxidant, anti-inflammatory, anticancer, and antimicrobial activities (Krumreich et al., 2018). However, the fresh avocado pulp has high levels of fat and moisture content, which caused the avocado to be a highly perishable fruit. To prolong the shelf life of avocado powder, the freeze-drying method is a suitable preservation method that prevents the loss of phytochemical compounds by a non-thermal process. Freeze-dried powders are typically produced in an amorphous state, and these solids theoretically undergo changes to crystallize in rheology at the glass transition temperature $\left(T_{g}\right)$, which is defined as the temperature at which glass transitions change to the rubber state (Chiou and Langrish, 2007).

At a given temperature, the $T_{g}$ of amorphous solids decreases with an increase in the water content, and when the $T_{g}$ decreases to a temperature lower than room temperature, the glassy material becomes rubbery. Since avocado has a large amount of carbohydrates, it is hypothesized to have low $T_{g}$ values and the glass to rubber transition occurs as it absorbs water, causing various undesirable physical changes such as shrinkage, crystallization, agglomeration and chemical changes, which affect its stability during production, processing, and handling (Chiou and Langrish, 2007). Consequently, it is important to elevate the $T_{g}$ of avocado powder to increase its stability at a given temperature above $T_{g}$. The 
study of water sorption isotherm equilibrated at varying water activities has been used to predict the shelf life of packed moisture-sensitive products for several powdered fruits (Yu et al., 2013; Cano-Higuita et al., 2015; Prasantha, 2018; Chang et al., 2019). Thus, the curves of $T_{g}$ versus water content and water sorption isotherms between water content and $\mathrm{a}_{\mathrm{w}}$ provide important criteria for the processing and storage stability of dried food systems (Telis et al., 2006; Goula and Adamopoulos, 2008).

The freeze-dried avocado powder is prone to caking due to the fatty acids and carbohydrates it contains during processing and storage. Caking is a deteriorative phenomenon involving agglomeration, consolidation, and adhesion, which cause serious problems in the food industry as it adversely affects the shelf life of the powders (Palzer and Sommer, 2010). Since caking of amorphous powders occurs in the rubbery state, the caking property of freeze-dried avocado powders is expected to be improved by adding high $T_{g}$ amorphous materials. Maltodextrin is commonly used because of its high $T_{g}$, bland flavor, and low price. Adding maltodextrin is hypothesized to increase $T_{g}$, reduce caking of the freeze-dried powder, prevent color changes due to the browning reaction, and prevent the loss of functionality of antioxidant compounds in the avocado.

The literature available on avocado powder produced through freeze-drying and its powdered qualities is very scarce. The relationship between the water sorption isotherm, $T_{g}$, caking, and maltodextrin contents at various concentrations is significantly valuable for quality measurement, including the effect of maltodextrin on the total phenolic contents and antioxidant ability, it should be addressed to improve overall properties of the freeze-dried avocado powder. Thus, the objective of this study was to understand moisture sorption characteristics, $T_{g}, \quad$ and physicochemical properties of avocado powder at various maltodextrin contents produced by a freezedrying technique. The water sorption behavior of the freeze-dried avocado powder was investigated at given $\mathrm{a}_{\mathrm{w}}$, and the $T_{g}$ of the mixtures were measured systematically. The caking property of the freeze-dried avocado mixtures was also studied. In addition, the effect of maltodextrin contents on color, the phenolic content, and the antioxidant capacities of freeze-dried avocado powder was determined.

\section{Materials and methods}

\subsection{Materials and reagents}

Avocados (Persea americana Mill.) were bought at a local market. Maltodextrin DE10 (Ingredion, food-grade) was used as a drying agent. 6-Hydroxy-2,5,7,8tetramethylchroman-2-carboxylic acid (Trolox) and 1,1diphenyl-2-picrylhydrazyl (DPPH) were purchased from Sigma-Aldrich (St. Louis, MO). Folin-Ciocalteu reagent and other chemicals were products of Fisher Scientific (Pittsburg, PA). All other materials used were of analytical grade.

\subsection{Freeze-dried avocado powder preparation}

Initially, the avocado was washed thoroughly, and the peel along with the core was removed. The avocado pulp was placed in a blade homogenizer and mixed with maltodextrin at various dry-weight fractions including $20 \%, 40 \%, 60 \%$ and $80 \%$ of the total solid content using a homogenizer (T10 Ultra-turrax, IKA, Germany) at 500 rpm for 5 mins. The obtained avocado samples were identified by the maltodextrin weight fraction. For example, the mixture with $80 \%$ avocado and $20 \%$ maltodextrin $(\mathrm{v} / \mathrm{v})$ is referred to as "A4M1". Freeze drying was performed in a laboratory-scale freeze dryer (Christ Alpha, Germany), and the samples were subjected to freezing in static air in a freezer at $-80^{\circ} \mathrm{C}$ until processing time. Then, the frozen sample was taken to the freeze dryer at $-50^{\circ} \mathrm{C}$ for $72 \mathrm{hrs}$ under pressure below 0.11 mbar. The freeze-dried avocado products were milled using a grinder and stored in a desiccator until use.

\subsection{Water activity}

Water activity was defined by the partial vapor pressure of water in food products divided by the partial vapor pressure of pure water at the same temperature. The water activity of the freeze-dried avocado powder was measured using an AquaLab 4TE (Meter Group Inc., USA) at $25^{\circ} \mathrm{C}$.

\subsection{Water sorption isotherms}

The equilibrium water contents of the avocado powders were determined using the static gravimetric method described by Yu et al. (2013) and Cano-Higuita et al. (2015). Freeze-dried avocado samples of approximately $0.5 \mathrm{~g}$ were placed in an aluminum dish and vacuum-dried at $80^{\circ} \mathrm{C}$ for $6 \mathrm{hrs}$ to reduce their water content. The fully dried samples were placed in hermetic glass jars containing different saturated salt solutions to expose them to various $\mathrm{a}_{\mathrm{w}}$ conditions at $25^{\circ} \mathrm{C}$. Eight saturated salt solutions including $\mathrm{LiCl}\left(\mathrm{a}_{\mathrm{w}}=0.113\right)$, $\mathrm{CH}_{3} \operatorname{COOK}\left(\mathrm{a}_{\mathrm{w}}=0.225\right), \mathrm{MgCl}_{2}\left(\mathrm{a}_{\mathrm{w}}=0.328\right), \mathrm{K}_{2} \mathrm{CO}_{3}\left(\mathrm{a}_{\mathrm{w}}\right.$ $=0.432), \operatorname{Mg}\left(\mathrm{NO}_{3}\right)_{2}\left(\mathrm{a}_{\mathrm{w}}=0.529\right), \mathrm{NaBr}\left(\mathrm{a}_{\mathrm{w}}=0.576\right)$, and $\mathrm{NaCl}\left(\mathrm{a}_{\mathrm{w}}=0.753\right)$ were prepared to provide the controlled water activity values. Freeze-dried samples were weighed periodically during equilibration until no difference $>0.001 \mathrm{~g}$ in weight between measurements was seen. The required equilibration time was four 
weeks, and the equilibrium water content of each sample was evaluated gravimetrically by drying samples at $105^{\circ}$ $\mathrm{C}$ for $16 \mathrm{hrs}$. The measurements were performed in triplicate, and the results were averaged. The water sorption isotherm was analyzed by the Guggenheim, Anderson, and de Boer (GAB) model.

$$
\mathrm{W}_{\mathrm{a}}=\frac{\mathrm{w}_{\mathrm{m}} \cdot C \cdot K \cdot \mathrm{a}_{\mathrm{w}}}{\left(1-K \cdot \mathrm{a}_{\mathrm{w}}\right) \cdot\left(1+(C-1) \cdot K \cdot \mathrm{a}_{\mathrm{w}}\right)}
$$

In the model, $\mathrm{W}_{\mathrm{e}}$ (g water/g solid) is the equilibrium water content, $\mathrm{W}_{\mathrm{m}}$ (g water/g solid) is the amount of water adsorbed strongly to specific sites on the surface of the material (monolayer water), and $C$ and $K$ are correction factors for monolayer and multilayer sorption properties, respectively (Cano-Higuita et al., 2015).

\subsection{Glass transition temperature $\left(T_{g}\right)$}

The effect of the water content on the $T_{g}$ of avocado samples was investigated using differential scanning calorimetry (DSC 120, Seiko Instruments Inc., Tokyo, Japan) and a system for temperature control using liquid nitrogen. The DSC temperature and heat flux were calibrated using distilled water and indium. The samples were exposed to various water activities $(0.113,0.225$, $0.328,0.432,0.529,0.649$, and 0.753 ) by adsorption process to the weight constancy. Then, samples of 5-10 $\mathrm{mg}$ were placed into aluminum DSC pans and hermetically enclosed. An empty similar aluminum pan was used as a reference. To evaluate the $T_{g}$ of the anhydrous sample $\left(T_{g(a s)}\right)$, the vacuum-dried sample was placed into a DSC pan and then further dried at $105^{\circ} \mathrm{C}$ for $12 \mathrm{hrs}$ before enclosing the pan. DSC measurements were carried out at a heating rate of $10^{\circ} \mathrm{C} / \mathrm{min}$. The glass transition temperature was determined from the midpoint of the heat capacity changes. The measurements were conducted in duplicate, and the results were averaged. The glass transition temperature with moisture content relationship was modelled using the Gordon-Taylor equation.

$$
T_{g}=\frac{\left(1-X_{w}\right) \cdot T_{g(a y)}+k \cdot X_{w} \cdot T_{g(w)}}{\left(1-X_{w}\right)+k \cdot X_{w}}
$$

In the model, $T_{g(a s)}, T_{g(w)}, X_{w}$, and $k$ are the $T_{g}$ of the anhydrous sample $(\mathrm{K})$, the $T_{g}$ of water $(\mathrm{K})$, the weight fraction of water (dimensionless), and a constant (dimensionless), respectively. $T_{g(a s)}$ was determined experimentally, and $T_{g(w)}$ was set to $136 \mathrm{~K}$ based on the literature value (Cervenka et al., 2012).

\subsection{Degree of caking}

The degree of caking of all samples was evaluated using a sieving method reported by Farahnaky et al. (2016) with slight modifications. The freeze-dried sample was previously vacuum-dried at $60^{\circ} \mathrm{C}$ for $6 \mathrm{hrs}$, and the fully dried powder was then manually sieved at a
$425 \mathrm{~mm}$ aperture size (40 mesh) using an AS200 vibratory sieve shaker (Retsch, Hann, Germany). Each sample (approximately $0.5 \mathrm{~g}$ ) was equilibrated under various $\mathrm{a}_{\mathrm{w}}$ conditions $(0.113-0.861)$ at $25^{\circ} \mathrm{C}$ according to the procedures mentioned above. The equilibrated samples were vacuum-dried at $25^{\circ} \mathrm{C}$ for $6 \mathrm{hrs}$ and then weighed $\left(\mathrm{W}_{\mathrm{i}}\right)$ and sieved at $1410 \mathrm{~mm}$ aperture size $(14$ mesh) for 5 mins at $10 \mathrm{~mm}$ amplitude. The retained sample on the sieve was weighed $\left(\mathrm{W}_{\mathrm{r}}\right)$ and the degree of caking was calculated as the following equation.

$$
\text { Degree of caking }(\%)=\frac{\mathrm{W}_{\mathrm{r}}}{\mathrm{W}_{\mathrm{i}}} \times 100 \%
$$

The measurements were performed in triplicate, and the results were averaged.

\subsection{Color}

The color of the freeze-dried avocado powder was measured using a MiniScan XE Plus colorimeter (Hunterlab, Reston, USA) in the CIELAB color space. The values of $L^{*}, a^{*}$, and $b^{*}$ were determined, in which $L^{*}$ represents the lightness of the samples ranging from darkness to lightness $(0-100), a^{*}$ is a coordinate $(-120$ to 120$)$ representing the scale of green to red, with negative values for greenness and positive values for redness, and $b^{*}$ similarly represents negative values for blueness and positive values for yellowness. The changes of freeze-dried avocado powder in terms of color and browning reaction affected by maltodextrin were measured after storage of the samples at room temperature $\left(25^{\circ} \mathrm{C}\right)$ for 1 month. The color difference was calculated according to $\Delta E=\sqrt{\Delta L^{*}+\Delta a^{*}+\Delta b^{*}}$, and the browning index was calculated according to $B I=\frac{[100(x-0.31)]}{0.17}$ where $X=\frac{\left(a^{*}+1.75 L^{*}\right)}{\left(5.64 L^{*}+a^{*}-3.102 b^{*}\right)}$.

\subsection{Antioxidant properties}

The polyphenols in freeze-dried avocado samples were extracted to determine the total phenolic content and antioxidant activity. The content of approximately $0.5 \mathrm{~g}$ of the freeze-dried sample was extracted by dissolving it in $5 \mathrm{~mL}$ of acetone/water/acetic acid solvent at the ratio of 70:29.7:0.3 $\mathrm{v} / \mathrm{v} / \mathrm{v}$. The extract tube was vortexed for $30 \mathrm{~s}$, sonicated for $5 \mathrm{mins}$, allowed to stand at room temperature for $20 \mathrm{mins}$, and sonicated for another $5 \mathrm{~min}$. The mixture was then centrifuged at $1277 \times \mathrm{g}$ for $30 \mathrm{mins}$, and the supernatant was separated and kept at $-20^{\circ} \mathrm{C}$ for phenolic content and antioxidant capacity analyses.

\subsubsection{Total phenolic content}

The total phenolic content of each dried sample was determined following the Folin-Ciocalteu method described by Singleton et al. (1999) with slight modifications. Briefly, $20 \mu \mathrm{L}$ of the extract, gallic acid 
standard or blank were taken in separate test tubes, and $1.58 \mathrm{~mL}$ of distilled water was added to each, followed by adding $100 \mu \mathrm{L}$ of Folin-Ciocalteau reagent, mixing it thoroughly, and adding $300 \mu \mathrm{L}$ of sodium carbonate within 8 mins. The mixtures were vortexed immediately and allowed to stand in the dark for $30 \mathrm{mins}$ at room temperature. The absorbance was then measured at 765 $\mathrm{nm}$ using a UV-Vis spectrophotometer (Spectronic ${ }^{\mathrm{TM}}$ GENESYS ${ }^{\text {TM} 2, ~ T h e r m o ~ F i s h e r ~ S c i e n t i f i c, ~ W a l t h a m, ~}$ MA). Total phenolic content was calculated from a standard curve of gallic acid, and the results were expressed in mg gallic acid equivalent (GAE)/g of dried sample.

\subsubsection{Antioxidant activity}

Radical scavenging DPPH assay was also performed to measure the antioxidant activity of the freeze-dried avocado powder according to Ghafar et al. (2010) with slight modification. Briefly, $200 \mu \mathrm{L}$ of the extract was reacted with $2.8 \mathrm{~mL}$ of $100 \mu \mathrm{M}$ DPPH dissolved in methanol for $30 \mathrm{~min}$ in the dark. A control contained only DPPH solution, and $80 \%$ ethanol was used as a blank. The absorbance was then recorded at $515 \mathrm{~nm}$ using a UV-Vis spectrophotometer (Spectronic ${ }^{\mathrm{TM}}$ GENESYS ${ }^{\mathrm{TM}}$ 2, Thermo Fisher Scientific, Waltham, MA). A standard curve was obtained by using Trolox standard solution at various concentrations (ranging from 0.25 to $2 \mathrm{mmol}$ ) in $80 \%$ methanol. The samples were analysed in triplicate, and the results were expressed as millimole Trolox equivalents (TE) per $g$ of dried sample.

\subsection{Statistical analyses}

All of the experiments were performed in triplicate and the results were reported as the mean \pm standard error. Analysis of variance (ANOVA) was performed in SAS (version 9.4, SAS Institute Inc., NC, USA). The determination of significant differences among the system means was done by Duncan's multiple range tests. The significance level $(P$-value $)$ was set at 0.05 .

\section{Results and discussion}

The values of water activity $\left(\mathrm{a}_{\mathrm{w}}\right)$ of freeze-dried avocado samples ranged from 0.062 to 0.372 , which increased with increasing maltodextrin avocado ratios in the dried samples. The maltodextrin-free avocado sample showed the highest value, and the values showed the same trend as reported by Sonthipermpoon et al. (2006). According to the official quality and identity standard of powder production in Thailand, a water activity $<0.6$ is required for fruit and vegetable powder products to maintain the quality.

\subsection{Effects of maltodextrin on the water sorption isotherm of freeze-dried avocado powder}

To predict the moisture sorption property, the GAB model has extensively been used especially in powdered fruits and vegetables. The water sorption behaviour of the freeze-dried avocado samples constructed and modelled using the collected data at room temperature $\left(25 \pm 1^{\circ} \mathrm{C}\right)$ is shown in Figure 1. In the present investigation, it was observed that freeze-dried avocado samples took nearly 4 weeks to reach equilibrium. All samples showed the amount of water adsorbed as a function of water activity. At lower $\mathrm{a}_{\mathrm{w}}$ the slope of the curve was small, which relates to the adsorption of a monomolecular film of water. While increasing $a_{w}$ the slope increased rapidly corresponding to adsorption of additional layers over this monolayer at $\mathrm{a}_{\mathrm{w}} 0.529-0.753$. The water sorption isotherm shifted downwards with increasing maltodextrin content. This effect was more pronounced as the avocado ratio increased and from $\mathrm{a}_{\mathrm{w}}$ 0.529 onwards. The higher the avocado ratio in powdered sample maintained mostly an amorphous state during water sorption resulting in higher water absorbed which is consistent with when the crystallization of powder particles occurred during water sorption, the water content of the sample decreased drastically (Fukami et al., 2016). In the present study, all avocado powders exhibited a typical sigmoid-shaped curve characteristic of type II isotherms, which is typical of most food products. Also, equilibrium water content increased slowly at low water activity and rose steeply at high water activity, which is typical behaviour for substances with high carbohydrate content. Similar behaviour was observed by Fabra et al. (2011) while investigating the effect of maltodextrin on noni pulp.

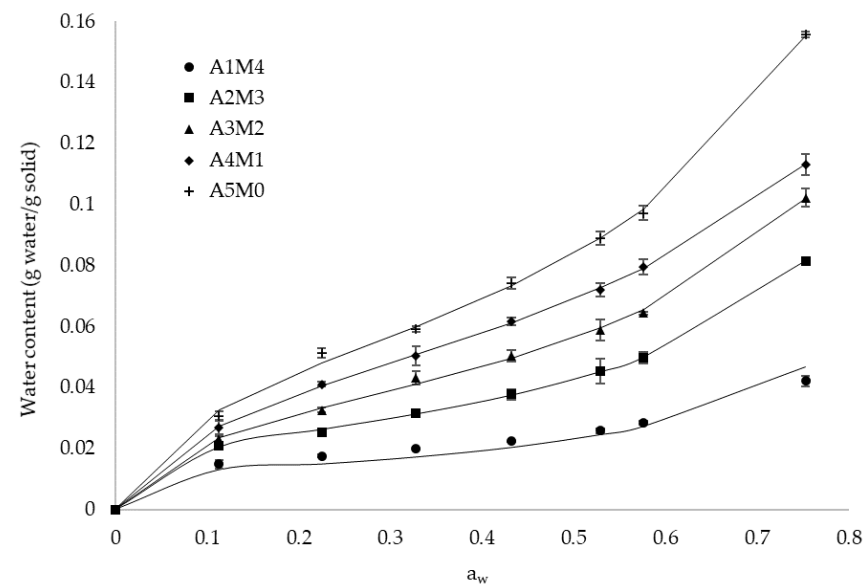

Figure 1. Water sorption isotherms of freeze-dried avocado samples at $25^{\circ} \mathrm{C}$. The solid lines were obtained by fitting the GAB equation to the experimental data. The values are expressed as mean $\pm \mathrm{SD}(\mathrm{n}=3)$.

The solid lines in Figure 1 were obtained by fitting the $\mathrm{GAB}$ equation to the data. The obtained GAB 
Table 1. GAB parameters by fitting experimental data of freeze-dried avocado samples

\begin{tabular}{cccccc}
\hline Sample & $\mathrm{W}_{\mathrm{m}}$ (g water/g dry solid) & $C$ & $K$ & $\mathrm{R}^{2}$ & RMSE \\
\hline A5M0 & 0.114 & 9.18 & 0.917 & 0.988 & 0.0166 \\
A4M1 & 0.109 & 11.39 & 0.813 & 0.991 & 0.0171 \\
A3M2 & 0.073 & 14.09 & 0.908 & 0.987 & 0.0101 \\
A2M3 & 0.048 & 30.53 & 0.959 & 0.997 & 0.0036 \\
A1M4 & 0.027 & 103.24 & 0.844 & 0.942 & 0.0034 \\
\hline
\end{tabular}

$\mathrm{R}^{2}$ means the correlation coefficient of determination, RMSE means the root means square error.

parameters $\left(\mathrm{W}_{\mathrm{m}}, C\right.$, and $\left.K\right)$ are summarized in Table 1 . The value of the monolayer moisture content $\left(\mathrm{W}_{\mathrm{m}}\right)$ implies the amount of water that is strongly adsorbed to specific sites on the powdered food surface corresponding to its physical stability. The small value of $\mathrm{W}_{\mathrm{m}}$ is considered to be the value at which a food product is the most stable (Andrade and Pérez, 2011). The $\mathrm{W}_{\mathrm{m}}$ values of the avocado samples ranged from 0.027 to $0.114 \mathrm{~g}$ water $/ \mathrm{g}$ solid, and $\mathrm{W}_{\mathrm{m}}$ increased with increasing avocado content. The relationship between maltodextrin content and $\mathrm{W}_{\mathrm{m}}$ was similar to those reported for other dried fruit powders, such as spray-dried noni pulp powder (Fabra et al., 2011), freeze-dried borojó (Mosquera et al., 2010), and freeze-dried mango pulp (Fongin et al., 2017).

The values of $C$ increased with increasing maltodextrin contents. Higher $C$ values indicate stronger binding bonds between water molecules and the sites (Quirijns et al., 2005). Thus, the effect of maltodextrin on $\mathrm{W}_{\mathrm{m}}$ and $C$ can be explained by the low hygroscopic property of maltodextrin than avocado, which contains several structural polysaccharides, including insoluble (cellulose and lignin) and soluble (hemicellulose and pectin) dietary fibres (Naveh et al., 2002). $K$ values ranged from 0.8132 to 0.9596 , which were close to 1 , indicating that the multilayer water behaves like water (Quirijns et al., 2005). In addition, adding maltodextrin did not lead to any notable changes in the $K$ values, which is similar to the report of Righetto and Netto (2005). Root means square error ranged from 0.0036 to 0.0171 with a high coefficient of determination $\left(\mathrm{R}^{2}>\right.$ 0.94), indicating the moisture sorption data was a sufficiently good fit for the GAB model. Since water sorption isotherm and the $a_{w}$ are safety and quality measures, especially in microbial growth, enzymatic changes, and non-enzymatic browning of dehydrated food products with low water content, this result could be useful as an important tool for predicting the behaviour of powdered avocado in processing, handling and storage.

\subsection{Effects of maltodextrin on the $T_{g}$ of freeze-dried avocado powder}

To determination of thermal transitions, the $T_{g}$ of freeze-dried avocado powder with various maltodextrin contents is shown in Table 2. It is obvious that that the lowest $T_{g}$ value corresponded to the powder without maltodextrin content. Avocado has a high fatty acid content ( $15 \%$ fat, $8.5 \%$ carbohydrates and $2 \%$ protein) which is known that the fruit has stickiness and low glass transition temperature when it is made as a powder. As shown in Table 1, the addition of MD led to an increase in the glass transition temperature of freeze-dried avocado. It is to be noted that the addition of maltodextrin resulted in a significant increased $T_{g}$ This behaviour is in agreement with knowledge of the $T_{g}$ of added high molecular weight anhydrous carbohydrates (Roos and Karel, 1991).

The glass transition temperature $\left(T_{g}\right)$ of freeze-dried avocado powders at various $a_{w}$ conditions is shown in Figure 2. The $T_{g}$ varied depending on the amount of water in the sample. The data obtained from high moisture content show water content greatly affected the $T_{g}$, which increased with increasing maltodextrin content at a given $\mathrm{a}_{\mathrm{w}}$. This result is consistent with several other food products such as jaggery granules (Jagannadha Rao et al., 2009), cassava starch (Sandoval et al., 2012), rice starch (Sablani et al., 2009), and strawberry puree (Galmarini et al., 2009). Thus, the present study shows the $T_{g}$ was sensitive to relative humidity when exposing the powder to water absorption.

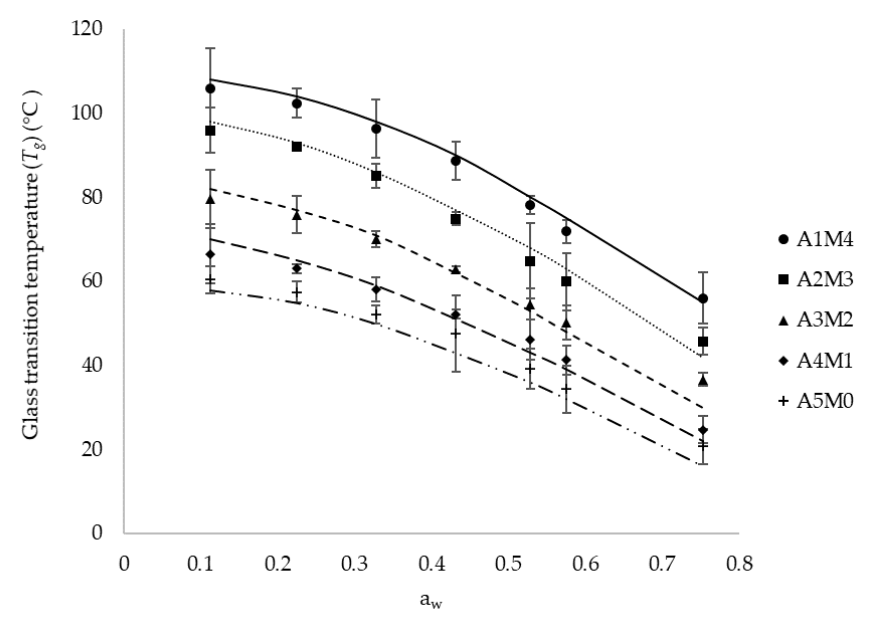

Figure 2. Glass transition temperature $(T g)$ of freeze-dried avocado powders at various $a_{w}$ conditions. The lines were obtained by fitting the Gordon-Taylor equation to the experimental data. The values are expressed as mean $\pm \mathrm{SD}(\mathrm{n}=$ $3)$. 
To predict $T_{g}$, the Gordon-Taylor equation has been successfully used and the estimated parameters are shown in Table 2. The results showed that the experimental data of $T_{g}$ fitted the Gordon-Taylor model well $\left(\mathrm{r}^{2} 0.946-0.998\right)$. The obtained $k$ parameters from the Gordon-Taylor model ranged from 3.26 and 6.48 . This parameter estimates the strength of the interaction between the components (Gordon and Taylor, 1952).

Table 2. Gordon-Taylor parameters of freeze-fried avocado powders.

\begin{tabular}{cccc}
\hline \multirow{2}{*}{ Sample } & \multirow{2}{*}{$T_{g}$ (onset) $\left({ }^{\circ} \mathrm{C}\right)$} & \multicolumn{2}{c}{ Parameters } \\
\cline { 3 - 4 } & & $k$ & $\mathrm{R}^{2}$ \\
\hline A5M0 & $53.53 \pm 8.30$ & 3.26 & 0.983 \\
A4M1 & $60.65 \pm 18.70$ & 4.58 & 0.993 \\
A3M2 & $79.31 \pm 8.62$ & 4.47 & 0.946 \\
A2M3 & $96.34 \pm 14.80$ & 5.15 & 0.997 \\
A1M4 & $105.67 \pm 23.74$ & 6.48 & 0.998 \\
\hline
\end{tabular}

$\mathrm{R}^{2}$ means the correlation coefficient of determination.

At below $T_{g}$, freeze-dried material is in an amorphous glassy state, which decreases molecular mobility, resulting in reduced physical and chemical changes. As the water content increases and solid content decreases, the $T_{g}$ decreases which change the glassy state of freeze-dried powders to the rubbery state as it absorbs water at a given temperature. Thus, increasing the maltodextrin content in the freeze-dried mixture increases the $T_{g}$ values to prevent its physical stability. The maltodextrin DE10 used in the present study has a high molecular weight, and its $T_{g}$ of dry matter is about $160^{\circ} \mathrm{C}$. Freeze-dried avocado powder without maltodextrin exhibits low $T_{g}$ values and becomes sticky. After increasing the maltodextrin content, the $T_{g}$ values of freeze-dried avocado powder increases due to increasing molecular weight. Thus, adding maltodextrin is a promising way to improve dehydration characteristics and to prolong product stability.

\subsection{Effects of maltodextrin on the degree of caking of the freeze-dried avocado powder}

The experiment set for caking measurement depends on the speed and amplitude conditions of sieving. To compare the caking property of freeze-dried avocado powders with various maltodextrin contents, a constant sieving condition among different samples was used to provide comparative information and the experiment was done in parallel with the water sorption isotherm. The effect of $a_{w}$ on the degree of caking of avocado powder is depicted in Figure 3. The degree of caking showed significantly decreases with increased maltodextrin at a certain $a_{w}$ condition and slightly increased when $a_{w}$ increased. From $\mathrm{a}_{\mathrm{w}} 0.576$ onwards, the degree of caking a trend of increase in all samples, and extreme caking
(75-94\%) was seen at an $\mathrm{a}_{\mathrm{w}}$ of 0.753 . In the samples with maltodextrin ratios of $60 \%$ (A2M3) and $80 \%$ (A1M4), the degree of caking increased dramatically from $4 \%$ to $75 \%$ and from $10 \%$ to $80 \%$, respectively. This suggests that the amorphous state in the freeze-dried sample with high avocado pulp had a greater effect on the caking phenomenon at all $\mathrm{a}_{\mathrm{w}}$ conditions. The study of Chang et al. (2019) stated that the addition of maltodextrin is able to compete with the solute particles from moisture, and maltodextrin acts as a moisture-protective barrier between the particles and also elevates the $T_{g}$ of the samples. The results of the present study showed that the degree of caking of an amorphous powder depended strongly on $T_{g}$, which are consistent with those of Aguilera et al. (1995). It suggested that the amorphous powder was physically glassy stable below $T_{g}$, and greater maltodextrin contents in the powdered samples were less sensitive to the caking due to their increased $T_{g}$ values. Therefore, maltodextrin could prevent caking of the freeze-dried samples.

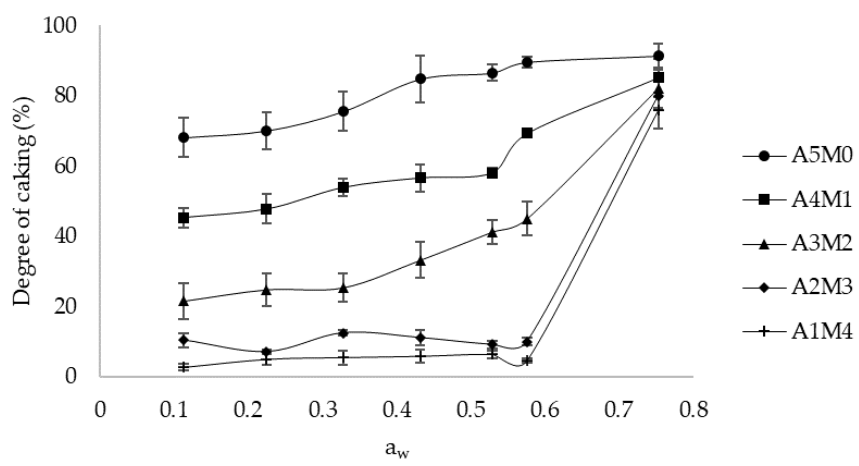

Figure 3. Effects of $a_{w}$ on the degree of caking of freeze-dried avocado samples. The values are expressed as mean \pm SD $(n=$ $3)$.

\subsection{Effects of maltodextrin on color of the freeze-dried avocado powder}

The colors of powdered products create visual attractiveness, which is a feature relevant to the acceptability of a product for consumers. The color parameters of freeze-dried avocado powder after 4 weeks of storage are presented in Table 3. As maltodextrin concentration increased, the brightness values of freezedried avocado powder increased, but yellowness decreased significantly $(p<0.05)$. The greenness of the powder was more pronounced when maltodextrin was added increasingly to the powders (A4M1 to A1M4) compared with pure avocado powder (A5M0). This indicates higher maltodextrin content in the samples was associated with brighter along with less yellowish and more greenish coloration when viewed with the naked eye. The differences between the corresponding color parameter of the samples and that of the initial value were shown in Table 3. The results showed a similar trend. Pure avocado powder sample without maltodextrin 
Table 3. Color parameters of freeze-dried avocado samples after 4 weeks of storage.

\begin{tabular}{cccccc}
\hline Sample & $L^{*}$ & $a^{*}$ & $b^{*}$ & $\Delta E$ & $B I$ \\
\hline A5M0 & $60.24 \pm 0.45^{\mathrm{d}}$ & $1.18 \pm 0.12^{\mathrm{d}}$ & $23.67 \pm 0.38^{\mathrm{e}}$ & 9.46 & 49.36 \\
A4M1 & $72.89 \pm 0.52^{\mathrm{c}}$ & $-1.80 \pm 0.43^{\mathrm{c}}$ & $18.91 \pm 0.79^{\mathrm{d}}$ & 8.69 & 27.07 \\
A3M2 & $79.42 \pm 0.21^{\mathrm{c}}$ & $-1.42 \pm 0.14^{\mathrm{b}}$ & $15.12 \pm 0.21^{\mathrm{c}}$ & 4.42 & 20.38 \\
A2M3 & $87.35 \pm 0.07^{\mathrm{b}}$ & $-1.02 \pm 0.15^{\mathrm{b}}$ & $10.50 \pm 0.29^{\mathrm{b}}$ & 3.6 & 11.49 \\
A1M4 & $90.63 \pm 0.12^{\mathrm{a}}$ & $-1.00 \pm 0.08^{\mathrm{a}}$ & $8.71 \pm 0.22^{\mathrm{a}}$ & 1.69 & 8.6 \\
\hline
\end{tabular}

Values are presented as mean \pm standard deviation $(n=6)$. Values with different superscript within the same column are significantly different $(\mathrm{p}<0.05)$.

showed dramatic visually unappealing changes in coloration while the changes were minimal when the maltodextrin was added to the powder. According to the browning index values of the avocado powders given in Table 3, the browning intensity of the freeze-dried avocado powder increased as a function of storage time and increasing the amount of maltodextrin significantly decreased the browning index value of the freeze-dried avocado powder $(p<0.05)$. The greenish and yellowish color of avocado is because of the naturally occurring carotenoid pigments, they are protected when a drying carrier agent is added. Wang et al. (2010) stated that the encapsulation with amorphous material acts as a physical barrier to prevent the dried powder from oxygen and light exposure, ensuring protection from phytochemical compound degradation.

\subsection{Total phenolic content and antioxidant capacities}

The total phenolic content and antioxidant activity were tested to evaluate the antioxidant capacity of phytochemical compounds remaining in the freeze-dried avocado powder. The Folin-Ciocalteu method works on the mechanism of oxidation-reduction reaction, whereas DPPH assay uses an electron transfer mechanism to stabilize radicals. As shown in Table 4, the total phenolic content was ranged from 8.6 to $48.6 \mathrm{GAE} \mathrm{mg} / \mathrm{g}$ dried sample and the DPPH scavenging ability was ranged from 0.7 to $17.5 \mu \mathrm{mol} \mathrm{TE} / \mathrm{g}$ dried sample. This was attributed to the fact that pure avocado powder without maltodextrin possesses the strongest antioxidant capacities, and this capacity was significantly diminished as a function of maltodextrin concentration. The result was similar to those of several studies (Chuaychan and Benjakul, 2016; Chuacharoen, 2017; Lachowicz et al., 2020). The effect of maltodextrin on the antioxidant capacity of vacuum-dried berry fruit powders measured by ABTS and FRAP assay was investigated by Lachowicz et al. (2020). The result indicated that the increased carrier concentration caused a 1.5-fold decrease in the antioxidant potential. Chuaychan and Benjakul (2016) also studied the effect of maltodextrin used as a carrier agent on the antioxidative activity of spray-dried gelatin powder. They observed the radical scavenging activity measured by DPPH assay was decreased when increased maltodextrin ratio.

Table 4. Total phenolic content and antioxidant ability in freeze-dried avocado samples.

\begin{tabular}{ccc}
\hline Sample & $\begin{array}{c}\text { Total phenolic content } \\
(\mathrm{mg} \text { GAE/g dry solid })\end{array}$ & $\begin{array}{c}\text { DPPH assay } \\
(\mu \mathrm{mol} \text { TE/g dry solid })\end{array}$ \\
\hline A5M0 & $48.6 \pm 1.7^{\mathrm{a}}$ & $17.5 \pm 5.8^{\mathrm{a}}$ \\
A4M1 & $29.2 \pm 3.3^{\mathrm{b}}$ & $6.2 \pm 3.1^{\mathrm{b}}$ \\
A3M2 & $17.9 \pm 2.1^{\mathrm{c}}$ & $2.0 \pm 2.9^{\mathrm{c}}$ \\
A2M3 & $9.1 \pm 0.6^{\mathrm{d}}$ & $1.4 \pm 0.7^{\mathrm{c}}$ \\
A1M4 & $8.6 \pm 0.7^{\mathrm{d}}$ & $0.7 \pm 0.4^{\mathrm{c}}$ \\
\hline
\end{tabular}

Values are presented as mean \pm standard deviation. Values with different superscript within the same column are significantly different $(\mathrm{p}<0.05)$.

\section{Conclusion}

In this study, the state diagram of freeze-dried avocado powder utilizing DSC was developed for measuring its glass transition temperatures. Increasing the addition of maltodextrin to the avocado resulted in the water sorption isotherm shifting downwards, increasing of $T_{g}$ value, improving the caking property, and diminishing color change and browning index of freeze-dried avocado powder during storage. However, the increased maltodextrin content decreased the antioxidant capacity of freeze-dried avocado powder. In sum, maltodextrin added as a drying agent increases the molecular weight of the freeze-dried avocado powder which prevents aggregation of the powder. The findings may be used to optimize the processing, storage, and packaging conditions of the freeze-dried avocado powder by adding maltodextrin to improve the stability of such products.

\section{Conflict of interest}

The authors declare no conflict of interest.

\section{Acknowledgments}

This research was funded by the Institute for Research and Development of Suan Sunandha Rajabhat University, grant number 1563. 


\section{References}

Aguilera, J., del Valle, J. and Karel, M. (1995). Caking phenomena in amorphous food powders. Trends in Food Science and Technology, 6(5), 149-155. https:// doi.org/10.1016/S0924-2244(00)89023-8

Alkhalaf, M.I., Alansari, W.S., Ibrahim, E.A. and Elhalwagy, M.E.A. (2019). Anti-oxidant, antiinflammatory and anti-cancer activities of avocado (Persea americana) fruit and seed extract. Journal of King Saud University - Science, 31(4), 1358-1362. https://doi.org/10.1016/j.jksus.2018.10.010

Andrade, R. and Pérez, C. (2011). Models of sorption isotherms for food: Uses and limitations. Vitae, Revista de la Facultad de Qu'imica Farmacéutica, $18,325-334$

Cano-Higuita, D.M., Villa-Vélez, H.A., Telis-Romero, J., Váquiro, H.A. and Telis, V.R.N. (2015). Influence of alternative drying aids on water sorption of spray dried mango mix powders: A thermodynamic approach. Food and Bioproducts Processing, 93, 19. https://doi.org/10.1016/j.fbp.2013.10.005

Cervenka, L., Kubínová, J., Juszczak, L. and Witczak, M. (2012). Moisture sorption isotherms and glass transition temperature of elecampe (Inula helenium L.) and burdock (Arctium lappa L.) roots at $25^{\circ} \mathrm{C}$. Ciencia y tecnología de los alimentos internacional, 18(1), 81-91. https:// doi.org/10.1177/1082013211414260

Chang, L.S., Karim, R., Sabo Mohammed, A., Chai, K.F. and Ghazali, H.M. (2019). Moisture sorption isotherm and shelf-life prediction of anticaking agent incorporated spray-dried soursop (Annona muricata L.) powder. Journal of Food Processing Engineering, 42(5), e13134. https://doi.org/10.1111/ jfpe. 13134

Chiou, D. and Langrish, T. (2007). Crystallization of Amorphous Components in Spray-Dried Powders. Drying Technology, 25(9), 1427-1435. https:// doi.org/10.1080/07373930701536718

Chuacharoen, T. (2017). Development of spray-dried lime juice powder with improved bioactive compound retention. Suan Sunandha Science and Technology Journal, 4(2), 7-12. https:// doi.org/10.14456/ssstj.2017.5

Chuaychan, S. and Benjakul, S. (2016). Effect of maltodextrin on characteristics and antioxidative activity of spray-dried powder of gelatin and gelatin hydrolysate from scales of spotted golden goatfish. Journal of Food Science and Technology, 53(9), 3583-3592. https://doi.org/10.1007/s13197-016-2340 $-7$
Fabra, M., Márquez, E., Castro, D. and Chiralt, A. (2011). Effect of maltodextrins in the water-contentwater activity-glass transition relationships of noni (Morinda citrifolia L.) pulp powder. Journal of Food Engineering, 103(1), 47-51. https://doi.org/10.1016/ j.jfoodeng.2010.09.018

Farahnaky, A., Mansoori, N., Majzoobi, M. and Badii, F. (2016). Physicochemical and sorption isotherm properties of date syrup powder: Antiplasticizing effect of maltodextrin. Food and Bioproducts Processing, 98, 133-141. https://doi.org/10.1016/ j.fbp.2016.01.003

Fongin, S., Kawai, K., Harnkarnsujarit, N. and Hagura, Y. (2017). Effects of water and maltodextrin on the glass transition temperature of freeze-dried mango pulp and an empirical model to predict plasticizing effect of water on dried fruits. Journal of Food Engineering, 210, 91-97. https://doi.org/10.1016/ j.jfoodeng.2017.04.025

Fukami, K., Kawai, K., Takeuchi, S., Harada, Y. and Hagura, Y. (2016). Effect of Water Content on the Glass Transition Temperature of Calcium Maltobionate and its Application to the Characterization of Non-Arrhenius Viscosity Behavior. Food Biophysics, 11(4), 410-416. https:// doi.org/10.1007/s11483-016-9455-2

Galmarini, M.V., Schebor, C., Zamora, M.C. and Chirife, J. (2009). The effect of trehalose, sucrose and maltodextrin addition on physicochemical and sensory aspects of freeze-dried strawberry puree. International Journal of Food Science and Technology, 44(10), 1869-1876. https:// doi.org/10.1111/j.1365-2621.2008.01890.x

Ghafar, M., Prasad, K.N., Weng, K.K. and Ismail, A. (2010). Flavonoid, hesperidin, total phenolic contents and antioxidant activities from Citrus species. African Journal of Biotechnology, 9(3), 326330.

Gordon, M. and Taylor, J.S. (1952). Ideal copolymers and the second-order transitions of synthetic rubbers. i. non-crystalline copolymers. Journal of Applied Chemistry, 2(9), 493-500. https://doi.org/10.1002/ jctb.5010020901

Goula, A.M. and Adamopoulos, K.G. (2008). Effect of Maltodextrin Addition during Spray Drying of Tomato Pulp in Dehumidified Air: I. Drying Kinetics and Product Recovery. Drying Technology, 26(6), 714-725. https:// doi.org/10.1080/07373930802046369

Krumreich, F.D., Borges, C.D., Mendonça, C.R.B., Jansen-Alves, C. and Zambiazi, R.C. (2018). Bioactive compounds and quality parameters of avocado oil obtained by different processes. Food 
Chemistry, 257, 376-381. https://doi.org/10.1016/ j.foodchem.2018.03.048

Lachowicz, S., Michalska-Ciechanowska, A. and Oszmiański, J. (2020). The Impact of Maltodextrin and Inulin on the Protection of Natural Antioxidants in Powders Made of Saskatoon Berry Fruit, Juice, and Pomace as Functional Food Ingredients. Molecules, 25(8), 1805. https://doi.org/10.3390/ molecules25081805

Mosquera, L., Moraga, G. and Martínez-Navarrete, N. (2010). Effect of maltodextrin on the stability of freeze-dried borojó (Borojoa patinoi Cuatrec.) powder. Journal of Food Engineering, 97(1), 72-78. https://doi.org/10.1016/j.jfoodeng.2009.09.017

Naveh, E., Werman, M., Sabo, E. and Neeman, I. (2002). Defatted avocado pulp reduces body weight and total hepatic fat but increases plasma cholesterol in male rats fed diets with cholesterol. The Journal of Nutrition, 132(7), 2015-2018. https:// doi.org/10.1093/jn/132.7.2015

Palzer, S. and Sommer, K. (2010). Caking of watersoluble amorphous and crystalline food powders. Food engineering interfaces, p. 491-514. New York, USA: Springer. https://doi.org/10.1007/978-14419-7475-4_19

Prasantha, B.D. (2018). Prediction of Moisture Adsorption Characteristics of Dehydrated Fruits Using the GAB Isotherm Model. Annals of Agricultural and Crop Sciences, 3(1), 1036.

Quirijns, E.J., van Boxtel, A.J., van Loon, W.K. and van Straten, G. (2005). Sorption isotherms, GAB parameters and isosteric heat of sorption. Journal of the Science of Food and Agriculture, 85(11), 18051814. https://doi.org/10.1002/jsfa.2140

Righetto, A. and Netto, F. (2005). Effect of Encapsulating Materials on Water Sorption, Glass Transition and Stability of Juice from Immature Acerola. International Journal of Food Properties, 8 (2), 337-346. https://doi.org/10.1081/JFP-200060262

Roos, Y. and Karel, M. (1991). Water and Molecular Weight Effects on Glass Transitions in Amorphous Carbohydrates and Carbohydrate Solutions. Journal of Food Science, 56(6), 1676-1681. https:// doi.org/10.1111/j.1365-2621.1991.tb08669.x

Sablani, S., Bruno, L., Kasapis, S. and Roopesh, M.S. (2009). Thermal transitions of rice: Development of a state diagram. Journal of Food Engineering, 90(1), 110-118. https://doi.org/10.1016/ j.jfoodeng.2008.06.008

Sandoval, A., Barreiro, J. and Müller, A. (2012). Moisture adsorption isotherms of amorphous cassava starch at different temperatures determined by a dynamic vapor sorption technique. Revista de la Facultad de Agronomia, 29(3), 475-493.

Singleton, V.L., Orthofer, R. and Lamuela-Raventós, R.M. (1999). Analysis of total phenols and other oxidation substrates and antioxidants by means of folin-ciocalteu reagent. Methods in Enzymology, 299, 152-178. https://doi.org/10.1016/S0076-6879 (99)99017-1

Sonthipermpoon, W., Suwonsichon, T., WittayaAreekul, S. and Wuttijumnong, P. (2006). Effect of maltodextrin on glass transition temperature and water activity of production banana flake. Kasetsart Journal (Natural Science), 40, 708-715.

Telis, V.R.N., Sobral, P.J.D.A. and Telis-Romero, J. (2006). Sorption Isotherm, Glass Transitions and State Diagram for Freeze-dried Plum Skin and Pulp. Food Science and Technology International, 12(3), 181-187. https://doi.org/10.1177/1082013206065953

Jagannadha Rao, P.V.K., Das, M. and Das, S. (2009). Effect of moisture content on glass transition and sticky point temperatures of sugarcane, palmyrapalm and date-palm jaggery granules. International Journal of Food Science and Technology, 45(1), 94104. 2621.2009.02108.x

Wang, W., Bostic, T.R. and Gu, L. (2010). Antioxidant capacities, procyanidins and pigments in avocados of different strains and cultivars. Food Chemistry, 122 (4), 1193-1198. https://doi.org/10.1016/ j.foodchem.2010.03.114

Yu, H., Zheng, Y. and Li, Y. (2013). Water Adsorption Isotherms and Storage Stability of Freeze-Dried Bovine Colostrum Powder. International Journal of Food Properties, 16(8), 1764-1775. https:// doi.org/10.1080/10942912.2011.608177 